\title{
The jellyfish fishery in Mexico
}

\author{
Juana López-Martínez*, Javier Álvarez-Tello \\ Centro de Investigaciones Biológicas del Noroeste, S.C. (CIBNOR), Unidad Sonora, Campus Guaymas, Guaymas, México; \\ *Corresponding Author: jlopez04@cibnor.mx
}

Received 26 April 2013; revised 26 May 2013; accepted 15 June 2013

Copyright (C 2013 Juana López-Martínez, Javier Álvarez-Tello. This is an open access article distributed under the Creative Commons Attribution License, which permits unrestricted use, distribution, and reproduction in any medium, provided the original work is properly cited.

\begin{abstract}
Jellyfish has been captured in Asia for $\mathbf{1 7 0 0}$ years, and it has been considered a delicacy. Since the 70s important jellyfish fisheries have developed in several parts of the world, with catches increasing exponentially, reaching 500,000 tons per year in the mid-nineties. In Mexico, only the cannonball jellyfish Stomolophus meleagris is captured commercially. Most of the capture of this jellyfish species is obtained within the Gulf of California, specifically in the state of Sonora. The total reported capture in 2010 was 16,581 metric $t$ and 14,220 in 2011. With these capture volumes jellyfish was ranked as the third most important fishing resource in the state of Sonora. The fishing season in Sonora is from April to May; a total of 4 or 5 weeks, and the catch per unit effort is around 3 tons by trip. Currently, there are nine jellyfish marketing companies, with about 20 processing plants distributed along the coast of Sonora, primarily in Guaymas, Kino Bay, and Puerto Peñasco. Although the process is simple, the large amounts of jellyfish required and the need to optimize production costs make jellyfish processing an intense activity that employs hundreds of people during the fishing season, becoming an alternative employment for the people who depend on the fishing industry.
\end{abstract}

Keywords: Jellyfish; Gulf of California;

Stomolophus meleagris; Sonora

\section{INTRODUCTION}

Jellyfish belongs to phylum cnidaria that also includes hydra, anemones, and corals. They are organisms that can be seen swimming in the sea surface, and are popularly known as "aguamala" (bad-water) in Mexico (Fig- ure 1), because some species secrete painful neurotoxic, even deadly, venom. Globally there has been a slight increase of individuals in this group of organisms during the last decades [1], but in some countries as Australia, jellyfish is considered a plague, so in response the government developed programs to control them. Among the possible causes of the increase of jellyfish population, an increase in water temperature due to global warming $[2,3]$, reduction of predators by overfishing, and water pollution $[4,5]$ have been mentioned. Waste discharge into the sea, and in general, the increment of pollution in coastal waters facilitate proliferation of these species since nitrogen compounds provide a suitable environment for the growth of organisms in which jellyfish feed.

Currently, there are investigations in several countries to assess the potential changes in marine ecosystems generated by the increase in jellyfish. Some of the most common are the moon jellyfish, Portuguese man-of-war (one of the most dangerous), and cannonball jellyfish, among others. The latter belongs to the genus Stomolophus, which is abundant in the Gulf of Mexico and the Pacific Ocean. In this region of the sea, Stomolophus meleagris can be found from the northern coast of

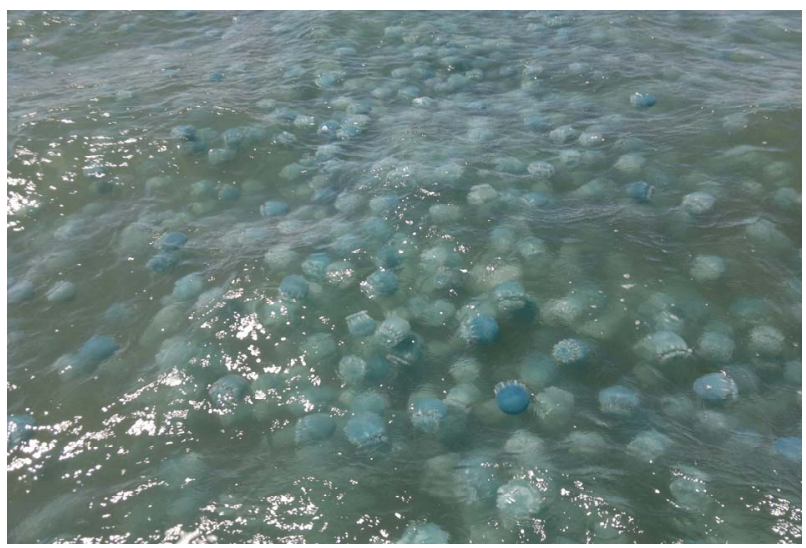

Figure 1. Appearance of jellyfish in the sea. 
Sonora in the Gulf of California to Ecuador, in South America. It is identifiable by its ball-shaped (hence also known as bulb and mushroom jellyfish) and blue color although there are also white and brown varieties. This species is also easily distinguished on the sea surface because it measures up to $15 \mathrm{~cm}$ in length and has an umbrella-shaped cover (bell); under the bell there is a rough trunk (manubrium) with a central hole where the oral arms, whose name comes from their dual function of catching and leading the food to the mouth, are located. The inner side of jellyfish is odd, since practically no organs are observed, and its structure is more similar to a gelatinous sculpture, while its movement is limited to the contractions of the bell at a rate of 2 pulses per second.

Cannonball jellyfish feed on zooplankton (eggs, larvae, juveniles, and adults of various marine species). It is a voracious predator [6] species with two stages in its life cycle, one as a jellyfish (observed directly under the sea surface), and the other one as a polyp (inhabiting the sea bottom) [7]. The first phase is the free form of life and sexual reproduction of the species; there are males and females, both release gametes to the aqueous medium, so fertilization is carried out externally.

From each fertilized egg a larva called planula is born; after a brief period of free swimming, the planula is fixed at the bottom and becomes an immature polyp (scyphistoma); it can live for several years (period when it reproduces asexually), whereas in the jellyfish stage it survives only from 3 to 6 months. When environmental conditions are favorable, the polyp begins a division process (strobilation) and generates an ephyra (swimming larva, originated by a process of asexual reproduction), forming a miniature jellyfish when detached and growing to an adult restarting the cycle (Figure 2).

The entire body of the jellyfish is edible [8]; its ge-

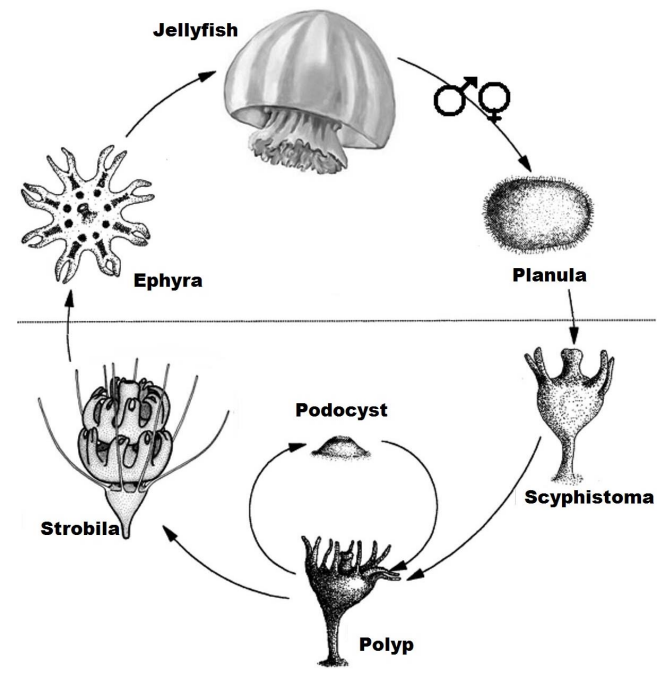

Figure 2. Life cycle of the cannonball jellyfish (Modified from Calder, 1982). latinous consistency becomes crispy undergoing a salting-drying process, so it is considered a delicacy in Chinese cooking [9]. The two main parts of the jellyfish, manubrium and bell, have a very similar constitution, but they are processed and marketed separately.

\section{JELLYFISH FISHERIES IN THE WORLD}

Jellyfish have been captured in Asia for 1700 years. China was the first country to use the jellyfish as food [10] and was soon followed by other Asian countries. Only jellyfish belonging to the order Rhizostomeae are being harvested for food because they are larger and have a more rigid body than others [9,11]. Dried jellyfish is considered a delicacy in many Asian cities and is also believed to have medicinal properties, so it has been traditionally used to treat conditions such as arthritis, hypertension, back pain, and ulcers, while softening skin and improving digestion [8]. In the rest of the world, important fisheries have developed since the 70 s with catches increasing exponentially, reaching 500,000 t per year in the mid-nineties (Figure 3). Most of the catches are from the west and northwest Pacific Ocean and the eastern Indian Ocean. Besides China, other countries with extensive backgrounds in the fishery (more than 25 years) include Indonesia, the Philippines, Malaysia, and Thailand, in fact, all catch records prior to 1969 came from Indonesia. Records of catches in the Philippines and Malaysia began in the late 1970s and during the 80s. Furthermore, a new fishery began in the Mediterranean in Turkey in 1984 while there have been experimental fisheries in other parts of the world [9,11]. Most of these experimental catches are not in the Food and Agriculture Organization of the United Nations (FAO) records.

Although traditionally confined to Asian waters, small numbers of jellyfish are harvested in Australia, the United States, the United Kingdom, Namibia, and Canada; catches are not trivial, for example, in 1996 they represented two thirds of the global catch of sharks and rays together (504,000 metric tons (mt), against 760,000 $\mathrm{mt}$ ), and exceeded lobster harvest. In monetary terms, they produced a total amount of million dollars (MD) to Japan (\$25 MD), Taiwan (\$20 MD), Korea (\$17 MD)

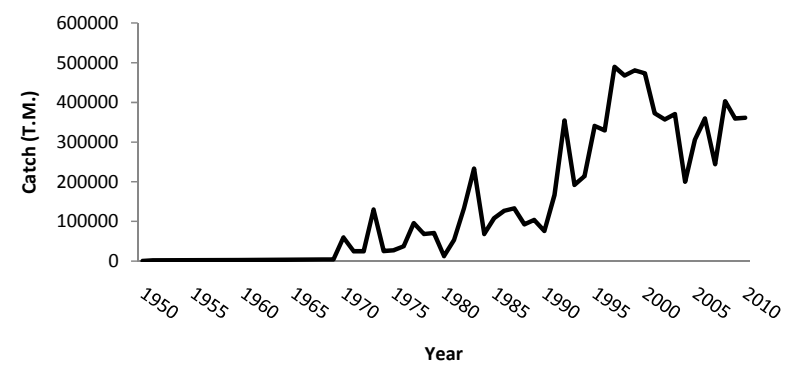

Figure 3. World catches of jellyfish. 
and the USA (\$6 MD).

The United States of America, Argentina, and Australia were the first non-Asian countries interested in the production of salted-dried jellyfish, developing cooperation programs between government, business, and research institutions and establishing a temporary regulation to capture this resource. While early jellyfish consumption records for its nutritional and medicinal properties come from China (300 AD. C.), currently the largest consumer is Japan, where about $50 \%$ of the jellyfish sold in the world is prepared [9] because of its delicious taste and its high collagen content.

\section{FISHING HARVESTING AND PROCESSING IN MEXICO}

In Mexico, only the cannonball jellyfish is used commercially, and although it had been recorded by Mexican scientists since the late $70 \mathrm{~s}$, in general very little is known about the species in national waters. Research activities and use of cannonball jellyfish began in 2000, when the first fishing permit was granted and a processing facility was built in the state of Tabasco, where they still conduct research nowadays [12].

Much of the biological findings on this species were conducted since 2004 as a result of the cooperation agreements between scientists and fishing companies. Much information about sites and seasonality of jellyfish blooms, their reproductive biology, growth, mortality, recruitment, as well as the relationship environmentjellyfish and settlement areas of polyps have been investigated [13]. Those investigations allowed to determine the potential use of this species and helped to integrate the resource datasheet that was inserted into the National Fisheries Chart 2010 [14] (policy instrument to regulate fisheries in Mexico) where among other things, it changed its utilization status to commercial fishing for the state of Sonora, while in other states it remains in development fishing mode (Sinaloa, Baja California, Nayarit, Oaxaca, Tabasco). In this datasheet administrative management measures are raised including catch size, fishing effort (number of boats to catch jellyfish), not overfishing the species, fishing gear allowed for capture, among others.

Jellyfish capture is performed on fiberglass boats, also called "pangas" in Mexico, involving three fishermen (with their respective nets); the capture is performed with scoop nets, consisting of a metal ring $0.4 \mathrm{~m}$ diameter, mounted on a handle 1.5 to $2.0 \mathrm{~m}$ long. A net of 0.07 to $0.12 \mathrm{~m}$ mesh size (maximum opening of each mesh comprising a net) is placed on the metal ring. Operating this gear is very simple because jellyfish usually swim in large groups on the surface at very low speed, making it possible to catch more than one animal in a single throw, so this maneuver does not require any training. It is important to note that fishing trips are often stressful, considering they are done under the sun at high temperatures, and a large number of jellyfish is required for good profits.

In the beginning of the fishery, the season was from March to July, even August, with only around 75 boats participating. By opening resource extraction to a greater number of users (currently 260 fishing vessels are Registered in addition to illegal fishing), the season was shortened, and now it starts in April and ends in May, with a total of a 4 or 5 -week season. The catch per unit effort is about $3 \mathrm{mt}$ per trip.

\subsection{Cannonball Jellyfish Fishery in Sonora Mexico}

Most of the capture of the cannonball jellyfish in Mexico is obtained within the Gulf of California, off the state of Sonora; the catch of jellyfish reported in the central-southern part of the state was $8,909 \mathrm{mt}$, which is less than that obtained in 2010 (16,581 mt) and 2011 (14,220 mt) (Figure 4). With these capture, jellyfish was ranked in 2010 as the third most important in the state, second only to sardine (87\%), and a similar volume to squid (3\%). In 2012 jellyfish fishing extended to the Upper Gulf of California, resulting in catches of large numbers of this species on the coasts of Sonora and Baja California. More than $\$ 1.5$ million USD were generated by this fishery in the upper Gulf and about 10,000 t (live weight) were captured; the price per kilogram ranged from \$0.19 to $\$ 0.21 \mathrm{USD}$, and in some extreme cases it paid up to $\$ 0.30$ USD. Most of the product was sold to China. The fishery in the upper Gulf acquired greater importance because it was performed from June to August when fishing activity decreases due to the scarcity of fish resources and the intense heat. The total catch of jellyfish in the Gulf of California during 2012 reached 18,909 mt only in the state of Sonora. This amount of catch allowed manufacturing approximately $5,640 \mathrm{mt}$ of products that were exported to China, which placed Mexico as the second supplier providing 21\%, just behind Bahrain with 27\% (Figure 5).

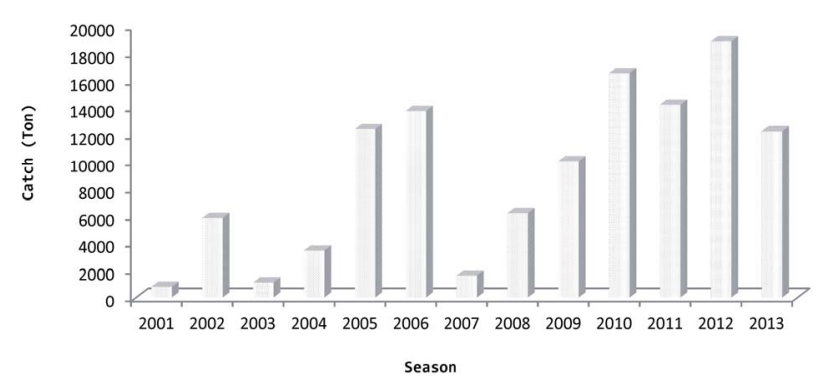

Figure 4. Annual capture of jellyfish in Sonora, Mexico from 2001 to 2013. 


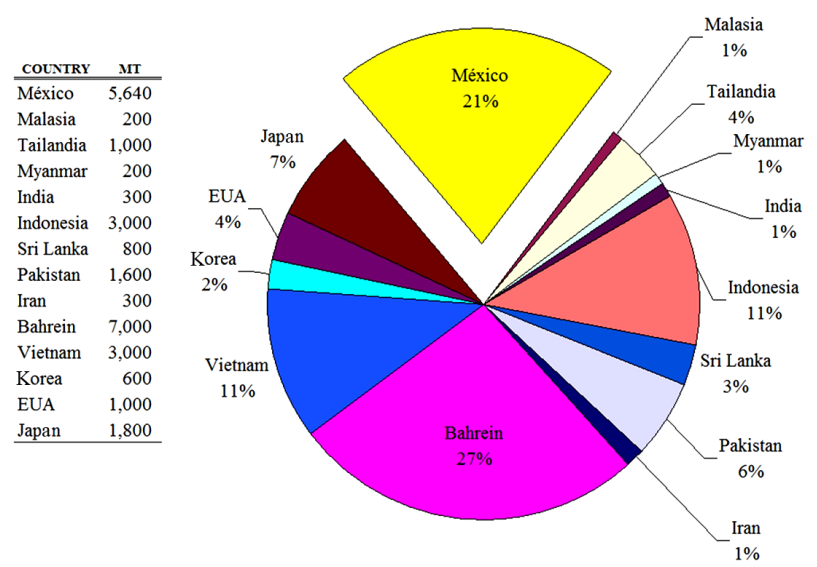

Figure 5. Leading suppliers of jellyfish to China during 2012.

\subsection{Industrialization and Employment}

Currently there are 9 jellyfish marketing companies in the State, with about 20 processing plants distributed along the coast of Sonora, primarily Guaymas, Bahia de Kino, and Puerto Peñasco. Jellyfish is fragile, so once captured the salting-drying process of conservation has to be performed immediately. The final product is packaged in 20-liter plastic pails (Figure 6). The yield of raw material varies from $10 \%$ - $25 \%$ depending on the country of destination, as each buyer sets its own product quality standards.

Although the process is simple, the large amounts of jellyfish required and the need to optimize production costs make manufacturing salted-dried jellyfish an intense activity that employs hundreds of people 24 hours a day during the fishing season, which makes it an alternative employment for a population in great need of jobs as all the people who depend on the fishing industry for their sustenance.

\section{CONCLUSIONS}

Considering the above, we conclude that the fishery for edible jellyfish Stomolophus meleagris is a consolidated activity in Mexico and competes with Southeast Asian countries, with long experience in this field. Compared to these countries, Mexican fishery has a greater potential, considering that most of the country resources are not even used, so this fishery can still grow and gain advantage in development and export capacity.

However, it is regrettable that the lack of awareness on jellyfish industry affects not only the species but also the fishermen and even participants in the fishery business. Short fishing seasons in Sonora, capturing smaller and smaller organisms, and the lack of application of management strategies make the future of this fishery uncertain in the long term.

Management based on biological knowledge of the species is required, integrating the new knowledge gen-

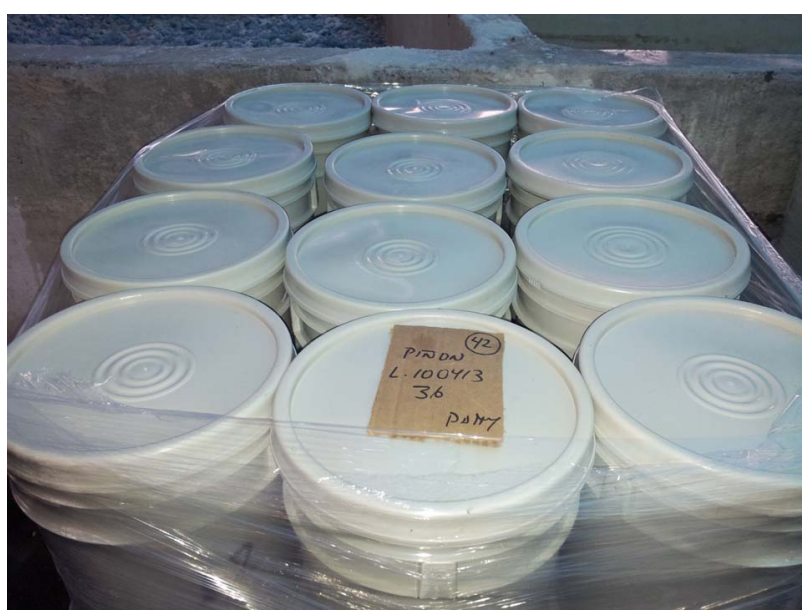

Figure 6. Final product presentation of the cannonball jellyfish for export to Asian markets.

erated in the relationship resource-environment to implement an ecosystem-based management. Ignorance of many aspects of the biology and fisheries of cannonball jellyfish is particularly evident in other states of Mexico such as Tabasco, Oaxaca, Nayarit, Sinaloa, and Baja California where scientific studies are far behind the development of this fishery.

There is no doubt that the fishing industry should devote more effort in reaching agreements to achieve a sustainable use of the jellyfish and avoid repeating the sad stories of other fisheries, such as sea cucumber and totoaba, which succumbed to marketer's ambition, and fishermen's lack of awareness.

\section{ACKNOWLEDGEMENTS}

This study was funded by CONACYT Basic Science project CB-2008-01 000000000106787. Thanks to Eloisa Herrera-Valdivia (Fisheries Laboratory) and Gustavo Padilla and David Urias (Coastal Management Laboratory) from Centro de Investigaciones Biológicas del Noroeste (CIBNOR Guaymas, Sonora, Carlos Rabago) and to Diana Dorantes (CIBNOR La Paz, B.C.S.) for English editing.

\section{REFERENCES}

[1] Condon, R.H., Duarte, C.M., Pitt, K.A., Robinson, K.L., Lucas, C.H., Sutherland, K.R., Mianzan, H.W., Bogeberg, M., Purcell, J.E., Decker, M.B., Uye, S., Madin, L.P., Brodeur, R.D., Haddock, S.H.D., Malej, A., Parry, G.D., Eriksen, E., Quinones, J., Acha, M., Harvey, M., Arthur, J.M. and Graham, W.M. (2012) Recurrent jellyfish blooms are a consequence of global oscillations. Proceedings of the National Academy of Sciences, 110, 1000-1005. doi:10.1073/pnas.1210920110

[2] Mills, C.E. (2001) Jellyfish blooms: Are populations increasing globally in response to changing ocean conditions. Hydrobiologia, 451, 55-68.

doi:10.1023/A:1011888006302 
[3] Brodeur, R.D., Beth Decker, M., Ciannelli, L., Purcell, J.E., Bond, N.A., Stabeno, P.J., Acuna, E. and Hunt Jr., G. L. (2008) Rise and fall of jellyfish in the eastern Bering Sea in relation to climate regime shifts. Progress in Oceanography, 77, 103-111. doi:10.1016/j.pocean.2008.03.017

[4] Pauly, D., Graham, W.M., Libralato, S., Morissette, L. and Palomares, M.L.D. (2009) Jellyfish in ecosystems, online databases, and ecosystem models. Hydrobiology, 616, 67-85. doi:10.1007/s10750-008-9583-X

[5] Purcell, J.E. (2012) Jellyfish and ctenophore blooms coincide with human proliferations and environmental perturbations. Annual Review of Marine Science, 4, 209-235. doi:10.1146/annurev-marine-120709-142751

[6] Larson, R.J. (1991) Diet, prey selection and daily ration of Stomolophus meleagris, a filter-feeding scyphomedusa from the NE Gulf of Mexico. Estuarine, Coastal and Shelf Science, 32, 511-525. doi:10.1016/0272-7714(91)90038-D

[7] Calder, D.R. (1982) Life history of the cannonball jellyfish, Stomolophus meleagris L. Agassiz, 1860 (Scyphozoa, Rhizostomida). Biological Bulletin, 162, 149-162. doi:10.2307/1540810
[8] Hsieh, Y.-H.P. (2001) Jellyfish as food. Hydrobiologia, 451, 11-17. doi:10.1023/A:1011875720415

[9] Omori, M. and Nakano, E. (2001) Jellyfish fisheries in Southeast Asia. Hydrobiologia, 451, 19-26. doi:10.1023/A:1011879821323

[10] Morikawa, T. (1984) Jellyfish. FAO INFOFISH Marketing Digest, 1, 37-39.

[11] Kitamura, M. and Omori, M. (2010) Synopsis of edible jellyfishes collected from Southeast Asia, with notes on jellyfish fisheries. Plankton Benthos Research, 5, 106118. doi:10.3800/pbr.5.106

[12] López-Martínez, J. and Álvarez-Tello, F.J. (2008) Medusa bola de cañón: Recurso de exportación. Ciencia y Desarrollo, 34, 8-15.

[13] López-Martínez, J., Ocampo, L., Rodríguez, J.R. and Hernández, N. (2009) Medusa Bola de cañón: Un recurso con potencial pesquero. BIOSIS, 1, 2-3.

[14] DOF (2010) Carta nacional pesquera. http://www.conapesca.sagarpa.gob.mx/wb/cona/actualiza cion_de_la_carta_nacional_pesquera_2010 